\title{
Telemedicine in Oncology and Reimbursement Policy During COVID-19 and Beyond
}

Sheetal M. Kircher, MD ${ }^{1,2}$; Mary Mulcahy, MD ${ }^{1,2}$; Aparna Kalyan, MD ${ }^{1,2}$; Christine B. Weldon, MBA ${ }^{2,3}$; Julia R. Trosman, $\mathrm{PhD}, \mathrm{MBA}^{2,3}$; and Al B. Benson III, MD ${ }^{1,2}$

\begin{abstract}
The first confirmed case of coronavirus disease 2019 (COVID-19) in the United States was reported on January 20, 2020. As of September 17, 2020, there were more than 6.6 million confirmed cases and 196,277 deaths. Limited data are available on outcomes of immunocompromised patients, but early published reports from China indicate that those with cancer have a 3.5 times higher risk of ICU admission, mechanical ventilation, or death than those without cancer. Because of the uncertain behavior of COVID-19, it has become imperative for practices to limit exposure to vulnerable patients. Telemedicine has been one of the cornerstones of caring for patients with cancer during the COVID-19 pandemic. This review provides an overview of reimbursement policy by public and private payers before and during the COVID-19 pandemic, describes implications in cancer care, and offers considerations for future reimbursement policy.
\end{abstract}

J Natl Compr Canc Netw, doi: 10.6004/jnccn.2020.7639 Published online September 30, 2020

\footnotetext{
${ }^{1}$ Robert H. Lurie Comprehensive Cancer Center of Northwestern University, Chicago; ${ }^{2}$ Northwestern University, Feinberg School of Medicine, Chicago; and ${ }^{3}$ Center for Business Models in Healthcare, Glencoe, Illinois.
}

\section{Rapid Implementation of Telemedicine in Oncology Practices}

The first confirmed case of coronavirus disease 2019 (COVID-19) in the United States was reported on January $20,2020 .{ }^{1}$ As of September 17, 2020, there were more than 6.6 million confirmed cases and 196,277 deaths. ${ }^{2}$ Limited data are available on outcomes of immunocompromised patients, but early published reports from China indicate that those with cancer have a 3.5 times higher risk of ICU admission, mechanical ventilation, or death than those without cancer. ${ }^{3,4}$ Because of the uncertain behavior of COVID-19, it has become imperative for practices to limit exposure to vulnerable patients.

Telemedicine has been one of the cornerstones of caring for patients with cancer during the COVID-19 pandemic. ${ }^{5-7}$ Telemedicine is commonly associated with video and/or audio consultations, but it can also include online patient portals, patient wellness apps, remote monitoring, and "store-and-forward" technologies that allow electronic transmission of medical information (ie, digital images, documents) through secure email and do not involve live interaction. This discussion focuses on live audio and/or video technology, because it has most dramatically increased as a result of COVID-19. Literally overnight, health systems and clinicians pivoted their practices from traditional brick-and-mortar clinics to telemedicine utilizing a range of resources from a simple telephone to video/audio platforms that allow clinicians to connect with the patient and family at multiple locations. In response to this need, the Coronavirus Preparedness and Response Supplemental Appropriations Act (CARES) was signed into law on March 6,2020 , and included a provision allowing the Secretary of Health and Human Services (HHS) to waive certain requirements for Medicare telehealth payment that existed prior to the pandemic.

The introduction of telemedicine into cancer care is moving rapidly for all stakeholders and is likely to play a role in future clinical practice. From a patient perspective, a cancer diagnosis and treatment confer significant indirect expenses, ${ }^{8}$ and telemedicine offers time- and 
cost-saving advantages, including reduced transportation, childcare, and time away from work. In cancer-specific populations, telemedicine has been shown to improve timeliness of diagnosis and treatment, access to care, and patient convenience. ${ }^{9-11}$ However, cited challenges include cost and access to technology, legal concerns related to the Health Insurance Portability and Accountability Act of 1996 (HIPAA) and/or liability, regulatory requirements, interference with the patient-oncologist relationship, and, importantly, reimbursement concerns. ${ }^{12}$ Although expanded coverage and reimbursement for telemedicine has been instituted during the current public health emergency, it remains unclear what policies will persist after this immediate crisis has subsided. For telemedicine to remain a viable component of cancer care beyond the pandemic, adequate and sustainable coverage and reimbursement policy will be necessary. This review provides an overview of reimbursement policy by public and private payers before and during the COVID-19 pandemic, describes implications in cancer care, and offers considerations for future reimbursement policy.

\section{Reimbursement Overview for Telemedicine by Public and Private Payers Before and During COVID-19}

\section{Levels of Reimbursement Policy Regulation for} Public and Private Payers

As the COVID-19 pandemic evolves rapidly, so has the guidance for coverage of telemedicine services. Insurance regulation has historically been controlled at the state level, but there are many areas where federal mandates supersede state laws (Table 1). Understanding the differing scopes of state versus federal policy is important to ensure that all insurance types have equitable policies.

Medicare is government-funded and regulated at the federal level. Private health insurance is administered through a group (employer-based) or nongroup (individual) market. Employer-based health insurance plans that are "self-insured" (also referred to as "self-funded") require the employer to pay directly into a plan that pays the benefit claims instead of using an insurance company, and a third party administers these plans. Selfinsured plans are regulated at the federal level by the Employee Retirement Income Security Act (ERISA), which sets minimum standards for health coverage. In $2019,61 \%$ of covered workers, including $17 \%$ of covered workers in small firms and $80 \%$ in large firms, were enrolled in plans that were either partially or completely self-funded. ${ }^{13}$ Employer-based health insurance plans that are "fully insured" require the employers to purchase healthcare coverage for their employees from an insurance company and pay a premium each year for that coverage. These plans are regulated at the state level. A major limitation of a state law is their narrow scope, because they affect only fully insured private insurance plans and state public plans (ie, Medicaid and state employee plans); self-insured and Medicare plans are not required to comply.

\section{Medicare Telemedicine Policy: Before and} During COVID-19

Prior to the pandemic, Medicare approached telehealth almost exclusively as a tool for rural areas, and only narrow geographic areas were eligible to use telehealth. The patient's geographic location was required to be in a Health Professional Shortage Area (HPSA) as defined by Health Resources and Services Administration (HRSA), or in a county outside of any Metropolitan Statistical Area (MSA) as defined by the US Census Bureau. In addition, the telemedicine service was required to be delivered to the patient at an eligible facility, which is limited to a provider office, hospital, critical access hospital, rural health clinic, federally qualified health center, skilled nursing facility, community mental health center, or hospital-based/critical access hospital-based renal dialysis center. Although telemedicine has been recognized in the literature as a potential opportunity, ${ }^{14}$ it has played a negligible role in most oncology practices, partly due to coverage eligibility restrictions.

Based on new waiver authority included in the CARES Act, ${ }^{15,16}$ the Secretary of HHS has waived certain restrictions on Medicare coverage of telehealth services for traditional Medicare beneficiaries during the COVID-19 public health emergency, effective for services starting on March 6, 2020, and continuing until resolution of the public health emergency. During the pandemic, Medicare expanded the list of eligible services, providers, geographic locations, and mode of telemedicine to include audio-only communication. For oncology practices, the combination of restrictions being lifted and the need to protect vulnerable patients has prompted rapid implementation. Table 2 provides a summary of telemedicine policy before and during COVID-19.

\section{Medicaid and Private Insurance Reimbursement for} Telemedicine Before and During COVID-19

Telemedicine reimbursement policies vary from state to state in the Medicaid and private (individual and fully funded) market.

If the state Medicaid program has managed care, telemedicine reimbursement can even vary from plan to plan. Prior to the provisions of the CARES Act, some key Medicaid coverage points included: 
Table 1. Insurance Types and Level of Regulation

\begin{tabular}{|c|c|c|c|}
\hline Type of Plan & Who It Covers & $\begin{array}{l}\text { Percentage of US } \\
\text { Population Covered }\end{array}$ & $\begin{array}{l}\text { Federal Versus } \\
\text { State Regulated }\end{array}$ \\
\hline Medicare & $\begin{array}{l}\text { Individuals aged } \geq 65 \text { years } \\
\text { Certain younger people with disabilities } \\
\text { Patients with end-stage renal disease }\end{array}$ & $14 \%^{a}$ & Federal \\
\hline $\begin{array}{l}\text { Private: group market } \\
\text { Self-insured } \\
\text { Fully insured }\end{array}$ & $\begin{array}{l}\text { Self-insured: employer (usually larger) operates their own health plan. } \\
\text { They may use a private insurance carrier to administer plan, but } \\
\text { financial risk/gain is maintained with the employer }\end{array}$ & $49 \%$ & Federal \\
\hline $\begin{array}{l}\text { Private: nongroup } \\
\text { (individual) market }\end{array}$ & $\begin{array}{l}\text { Individuals and/or family purchase if not eligible for public programs } \\
\text { and do not have the option to purchase adequate health insurance } \\
\text { from their employer because they are unemployed, self-employed, or } \\
\text { their employer does not offer it }\end{array}$ & $6 \%$ & $\begin{array}{l}\text { State }^{\mathrm{a}} \\
\text { Federally, ACA has } \\
\text { regulations to ensure } \\
\text { affordability and access }\end{array}$ \\
\hline $\begin{array}{l}\text { State employee health } \\
\text { benefit plans }\end{array}$ & Employees of the state (eg, teacher, police) & NA & State \\
\hline
\end{tabular}

Data from 2018 Kaiser Family Foundation Health Facts Data. Accessed June 29, 2020. Available at: https://www.kff.org/other/state-indicator/total-population. Abbreviations: ACA, Affordable Care Act; NA, not available.

andividuals who are "dual eligible," meaning they have both Medicaid and Medicare coverage, are categorized as Medicaid.

bEligible groups found at https://www.medicaid.gov/sites/default/files/2019-12/list-of-eligibility-groups.pdf.

- Fifty states and Washington, DC, provide reimbur sement for some form of live video in Medicaid fee-for-service

- Fourteen states provide reimbursement for storeand-forward (AK, AZ, CA, CT, GA, MD, MN, NV, $\mathrm{NM}, \mathrm{NY}, \mathrm{TN}, \mathrm{TX}, \mathrm{VA}$, and WA)

- Four additional jurisdictions (HI, MS, NH, and NJ) have laws requiring Medicaid reimburse for storeand-forward but, as of the creation of this edition, are yet to have any official Medicaid policy indicating this is occurring

- Twenty-two state Medicaid programs provide reimbursement for remote patient monitoring

- Two Medicaid programs (HI and NJ) have laws requiring Medicaid reimburse for remote patient monitoring

- Twenty-three states limit the type of facility that can serve as an originating site

- Thirty-four state Medicaid programs offer a transmission or facility fee when telehealth is used

Prior to COVID-19, The Kaiser Family Foundation's 2019 Employer Health Benefit Survey reported that large employers offering telehealth benefits increased from $27 \%$ to $82 \%$ from 2015 to 2019 . The largest employers, those with $\geq 5,000$ workers, are the most likely to cover telemedicine $(90 \%)$, whereas smaller firms, those with 50 to 199 workers, are least likely (65\%). In addition, 40 states and Washington, DC, currently have a law that governs private payer telehealth reimbursement policy. Despite high levels of coverage in the private market, in 2018 only
$2.4 \%$ of large group enrollees who had an outpatient office visit had at least one telemedicine visit. ${ }^{17}$

As a result of COVID-19, many states and private payers have acted to remove policy barriers to telehealth utilization, such as allowing for telephone visits, expanded covered services, no geographic location restrictions for the patient, and expansion of the originating site that will be eligible for a facility fee. A full list of state laws is on the Center for Connected Health Policy (CCHP) (https://www. cchpca.org/resources/covid-19-related-state-actions). A tool kit was also published by the Centers for Medicare and Medicaid Services (CMS; https://www.medicaid.gov/ medicaid/benefits/downloads/medicaid-chip-telehealthtoolkit.pdf). America's Health Insurance Plans (AHIP) has compiled a list of private payer telemedicine policy changes as a result of COVID-19 (https://www.ahip.org/healthinsurance-providers-respond-to-coronavirus-covid-19/\#B).

\section{Considerations for Future Telemedicine Reimbursement Policy Development}

Evidence on Impact, Outcomes, and Implementation Best Practices Are Needed to Support Reimbursement Policy

During the COVID-19 pandemic, many oncology practices have developed internal processes for implementation of telemedicine, and further systematic guidance for rapid implementation has recently been published..$^{18} \mathrm{In}$ addition, CMS has responded by expanding guidance and reimbursement for non-face-to-face encounters in the management of patients; however, it is unclear how 
Table 2. Summary of Pre- and Post-COVID-19 Medicare Policy and Implications for Oncology Practices

\begin{tabular}{|c|c|c|c|}
\hline Medicare Policy & Pre-COVID-19 & Modification Due to COVID-19 & Implications for Practices \\
\hline $\begin{array}{l}\text { Out-of-pocket } \\
\text { costs }\end{array}$ & Same amount as in-person service & $\begin{array}{l}\text { Increased flexibility to reduce or waive } \\
\text { patient cost } \\
\text { No cost-sharing for COVID-19 testing- } \\
\text { related services (eg, test, associated } \\
\text { clinician, emergency department visit) }\end{array}$ & $\begin{array}{l}\text { Patients must be informed that telemedicine visits } \\
\text { are billed for non-COVID-19 issues }\end{array}$ \\
\hline Eligible providers & $\begin{array}{l}\text { Limited types of providers } \\
\text { Excludes FQHC/RHC }\end{array}$ & $\begin{array}{l}\text { Added } \mathrm{FQHCs} / \mathrm{RHCs} \text {, physical/occupational } \\
\text { therapists, and speech } \\
\text { language pathologists }\end{array}$ & $\begin{array}{l}\text { Administrative and technology capacity needs to } \\
\text { be built }\end{array}$ \\
\hline Location of patient & $\begin{array}{l}\text { Originating site (patient's geographic } \\
\text { location) must be in an HPSA or a } \\
\text { county that is outside an MSA } \\
\text { Patient receives telemedicine service } \\
\text { at an eligible facility }\end{array}$ & $\begin{array}{l}\text { Site limitations are removed (can be at } \\
\text { home) }\end{array}$ & $\begin{array}{l}\text { Assess patient access to phone/video and } \\
\text { broadband connection }\end{array}$ \\
\hline Other additions & & Ig home and hospice eligibility duri & cy \\
\hline
\end{tabular}

Abbreviations: CMS, Centers for Medicare and Medicaid Services; CPT, Current Procedural Terminology; HPSA, Health Professional Shortage Area; OIG, Office of Inspector General; FQHS, federally qualified health centers; MSA, Metropolitan Statistical Area; RHC, rural health clinics.

${ }^{a} A$ list of telehealth services is available at: https://www.cms.gov/Medicare/Medicare-General-Information/Telehealth/Telehealth-Codes.

bPhysicians, nurse practitioners, physician assistants, nurse midwives, clinical nurse specialists, certified registered nurse anesthetists, clinical psychologists and clinical social workers, and registered dietitians or nutritionists.

cSee the Medicare Telehealth Payment Eligibility Analyzer, available at: https://data.hrsa.gov/tools/medicare/telehealth

dTechnologies that allow for the electronic transmission of medical information (eg, digital images, documents) through secure email communication and do not involve live interaction.

' CMS Interim Final Rule from March 31, 2020 states codes are covered and can be billed retroactively from March 1, 2020. Accessed on September 17, 2020.

Available at: https://www.cms.gov/files/document/covid-medicare-and-medicaid-ifc2.pdf

long these reimbursement provisions will continue. For successful long-term implementation of telemedicine in oncology and sustainable reimbursement from public and private payers, evidence must be compiled to assure that new models do not sacrifice quality or cause harm to patients. Professional and patient cancer organizations should take the lead to propose cancerspecific metrics and gather data on clinician and patient perspectives surrounding telemedicine so our collective experiences and "lessons learned" are reflected in future policy changes. It is critical that policy incorporate elements of telemedicine that improve patient care outcomes and abandon elements that either harm patients, health systems, and/or clinicians, or widen disparities.

\section{Access to Technology and Infrastructure \\ for Telemedicine}

Current telemedicine reimbursement policies allow both audio and video telecommunication systems that permit real-time communication. An assessment of technology capacity for both clinicians and patients is necessary to better understand if this requirement widens disparities.
Within the context of social determinants of health, there are factors that contribute to increased access barriers to telemedicine. Patients may live in a build environment that lacks broadband internet or has limited access to free public internet (eg, libraries). There is variability in digital technology literacy and education regarding changes in technology. Economic or housing instability can lead to inability to purchase and maintain devices or afford devices that have the capacity to work with proposed programs. ${ }^{19-21}$ In addition, cultural expectations regarding use of telemedicine or telemonitoring, including mistrust of either technology or the medical community, ${ }^{22}$ may impact patient engagement with telemedicine. ${ }^{23,24}$ For most communities, the use of smartphones is widespread; however, disparities exist in some populations, including among individuals aged $>65$ years, with less than a high school degree, who live in rural areas, and have low income. ${ }^{25}$ Some patients do not have access to a smartphone or computer with video or affordable monthly data plans. Patients with cancer may be at particular risk of underutilizing technology because the mean age at diagnosis is 66 years ${ }^{26}$; there is a high prevalence of multiple comorbidities ${ }^{27}$; and they may be 
receiving therapies that impact their physical functioning (eg, neuropathy, fatigue, cognitive dysfunction).

From a health system and clinician perspective, considerable investments in technology were made after the Patient Protection and Affordable Care Act (PPACA) mandate for electronic medical records. Despite these investments, many may not have the resources, facilities, or staffing to further invest in creating HIPAAcompliant video capacity to handle the demands of telemedicine (eg integration with electronic medical records, screensharing capability). Clinicians may need equipment such as headsets and video-equipped computers/tablets as well as a physical location to conduct these visits. Further evaluation is needed to better understand what additional resources would be necessary for health systems and clinics to provide both audio and video, and reimbursement should reflect this capacity.

\section{Under, Over, and Optimal Utilization}

Data exist suggesting that expensive services such as emergency departments (EDs) are overutilized, and strategies to promote prevention and screening services are underutilized. ${ }^{28-31}$ A key attraction of telehealth for health plans and employers is the potential savings involved in replacing physician office and ED visits with less expensive virtual visits. This could be especially salient in situations where it may not be necessary for a patient to be evaluated face-to-face, such as oral chemotherapy toxicity checks, survivorship education and surveillance, and genetics assessment. However, increased convenience may tap into unmet demand for healthcare, and new utilization may increase overall healthcare spending. This was demonstrated in a study of $>300,000$ commercial claims from 2011 through 2013 that explored patterns of utilization and spending for acute respiratory illnesses. The investigators estimated that $12 \%$ of telehealth visits replaced visits to other providers, and $88 \%$ represented new utilization. Net annual spending on acute respiratory illness increased $\$ 45$ per telehealth user. ${ }^{32}$ Overutilization may be prompted either from patient demand or provider demand as a result of misaligned financial incentives in a fee-for-service environment. ${ }^{33}$ Because of the risk for perverse financial incentives for clinicians, telemedicine should optimally be within payment models that align payment with value-based outcomes instead of fee-for-service. Providers' financial incentives must be aligned with telemedicine in order to produce desired outcomes. It will be important to evaluate telemedicine services over time with meaningful metrics, such as ED utilization and hospitalization, use of prevention and screening services, and patient expectations and acceptance of telemedicine interventions.
In addition, incorporation of telemedicine into clinical guidelines (eg, NCCN, ASCO) will help standardize and minimize overutilization or underutilization, define optimal utilization, and encourage payers to cover services deemed appropriate.

\section{Telemedicine Offers Access to Supportive Oncology Services}

Supportive oncology services are an established and essential component of cancer treatment, and are recommended in guidelines ${ }^{34-36}$ and required by accreditation bodies. ${ }^{37,38}$ These services can include social work, nutrition, physical therapy, navigators, spiritual care, financial counseling, palliative care, psychology, and psychiatry. Significant barriers, however, prevent consistent availability and delivery of supportive oncology services, including insufficient fee-for-service reimbursement and the lack of available specialists and staff. With the pervasive trend toward alternative payment models, value-based care, and now telemedicine, the inclusion of comprehensive supportive oncology care in emerging payment structures becomes particularly important for sustaining quality of cancer care. As the oncology community compiles data on our experiences with telemedicine, we urge data collection in not only billable clinician encounters (eg, claims data) but also the "unbillable" work performed by nurses and supportive oncology team members to determine whether telemedicine could offer increased access to these essential services. Telemedicine could enable a more efficient delivery of supportive oncology services; however, sustainability of this approach would rely on adequate reimbursement.

\section{Clinical Trials}

Cancer clinical trials establish the evidence base for clinical practice; however, fewer than 1 in 20 adult patients with cancer enroll. ${ }^{39}$ Barriers to clinical trial participation are multifactorial, and include those limiting access, such as transportation, travel costs, and availability of child care. ${ }^{39}$ In addition, mistrust of research and the medical community are important reasons for lack of participation, especially among racial/ethnic minorities. ${ }^{40-42}$ The mistrust of technology, research, and the medical community also presents challenges to the use of telemedicine in clinical research.

Interest has been shown in virtual trials (also referred to as decentralized trials, remote trials, direct-topatient trials, and hybrid trials) to potentially help widen the pool of trial participants, increase retention, improve the quality of data, and improve the overall patient experience. ${ }^{43-45}$ During COVID-19, the FDA 
issued guidance on conducting aspects of ongoing clinical trials with virtual assessments. ${ }^{46}$ Efficiency, cost, and patient safety may be enhanced by participant assessments via telemedicine. Clinical trial design and infrastructure should integrate aspects of telemedicine and include evaluation of this new element of care delivery.

\section{Patients in Rural Health Settings}

Patients in rural settings are especially vulnerable to access challenges and are therefore underrepresented in most studies. As long as there are sufficient technologic resources available (eg, video capability, broadband internet access), telemedicine may overcome these barriers and has been shown to be acceptable to both patients and clinicians. ${ }^{47-50}$ Research suggests that once treatment has concluded, rural survivors can receive effective supportive care in or near their homes via telemedicine, reducing the need to travel long distances. ${ }^{51-53}$ CMS has reimbursed for telemedicine services since 1998; however, these reimbursements have been limited by the restriction that the Medicare beneficiary be located in a rural HPSA or county outside of an MSA. These geographic restrictions have been lifted with COVID-19, and future policy should carefully consider expanding or even abandoning geographic location restrictions in some cases, such as when enrolled in a clinical trial or when patients seek a second opinion.

\section{Research Agenda and Policy Recommendations}

From traditional scientific standards, research is moving fast to understand the epidemiology of COVID-19 and develop diagnostic and therapeutic options. Out of necessity, cancer care delivery utilizing telemedicine has also evolved rapidly, and more robust research is needed to study this unexpected natural experiment to guide future research and policy agendas. Development and standardizing of oncology-specific metrics for telemedicine can leverage existing work by the National Quality Forum (NFQ). In 2017, NFQ published a telehealth framework that reviewed existing and future telemedicine metrics and proposed measures with the following 6 domains: travel, timeliness of care, actionable information, added value of telehealth to provide evidencebased best practices, patient empowerment, and care coordination. ${ }^{54}$ Additional cancer-specific measures could help evaluate whether telemedicine is a more efficient method of delivering comprehensive supportive oncology services such as social work, nutrition, navigation, and psychology. Accreditation and/or certification bodies such as ASCO Quality Oncology Practice Initiative (QOPI) and the American College of Surgeons National Surgical Quality Improvement Program (ACS NSQIP) could help collect data to understand patterns of access and outcomes related to telemedicine. Based on these data, guidelines can be developed to define appropriate settings for telemedicine.

\section{Conclusions}

As we move forward, thoughtful and evidence-based policy can potentially improve accessibility of medical and supportive oncology services. CMS has responded rapidly to the immediate crisis, and many believe that how we practice medicine may be forever changed to include this technology. We should learn from this natural experiment and implement necessary infrastructure to build technology capacity, maintain HIPAA compliance across different platforms, and address reimbursement challenges, including protections against medical billing abuse. For all stakeholders to capitalize on this unplanned opportunity to implement telemedicine, a partnership needs to be created among government agencies, clinicians, researchers, patient advocacy groups, and private-sector organizations to rapidly test, evaluate, deploy, and pay for new telemedicine care models.

\section{Submitted May 20, 2020; accepted for publication August 13, 2020}

Disclosures: The authors have disclosed that they have no financial interests, arrangements, or affiliations with the manufacturers of any products discussed in this article or their competitors.

Correspondence: Sheetal M. Kircher, MD, Robert H. Lurie Comprehensive Cancer Center of Northwestern University, 676 North St. Clair, Suite 850,

Chicago, IL 60611. Email: sheetal.kircher@nm.org

\section{References}

1. Holshue ML, DeBolt C, Lindquist $\mathrm{S}$, et al. First case of 2019 novel coronavirus in the united states. N Engl J Med 2020;382:929-936.

2. Centers for Disease Control and Prevention. Coronavirus Disease 2019 (COVID-19). Accessed September 17, 2020. Available at: https://www. cdc.gov/coronavirus/2019-ncov/cases-updates/cases-in-us.html

3. Liang W, Guan W, Chen R, et al. Cancer patients in SARS-CoV-2 infection: a nationwide analysis in China. Lancet Oncol 2020;21:335-337.

4. Wang H, Zhang L. Risk of COVID-19 for patients with cancer. Lancet Oncol 2020;21:e181.

5. Hollander JE, Carr BG. Virtually perfect? Telemedicine for Covid-19. N Engl J Med 2020:382:1679-1681.

6. Webster P. Virtual health care in the era of COVID-19. Lancet 2020;395 1180-1181.

7. Meti N, Rossos PG, Cheung MC, et al. Virtual cancer care during and beyond the COVID-19 pandemic: we need to get it right [published online May 13, 2020]. JCO Oncol Pract, doi: 10.1200/OP.20.00281

8. Pisu M, Henrikson NB, Banegas MP, et al. Costs of cancer along the care continuum: what we can expect based on recent literature. Cancer 2018 , 124:4181-4191.

9. Chumbler NR, Kobb R, Harris L, et al. Healthcare utilization among veterans undergoing chemotherapy: the impact of a cancer care coordination/hometelehealth program. J Ambul Care Manage 2007;30:308-317. 
10. Binder B, Hofmann-Wellenhof R, Salmhofer W, et al. Teledermatological monitoring of leg ulcers in cooperation with home care nurses. Arch Dermatol 2007;143:1511-1514.

11. Gordon J. Dermatologic assessment from a distance: the use of teledermatology in an outpatient chemotherapy infusion center. Clin J Oncol Nurs 2012;16:418-420.

12. Zachrison KS, Boggs KM, Hayden EM, et al. Understanding barriers to telemedicine implementation in rural emergency departments. Ann Emerg Med 2020;75:392-399.

13. Kaiser Family Foundation. 2019 Employer Health Benefits Survey. Accessed April 27, 2020. Available at: https://www.kff.org/report-section/ ehbs-2019-summary-of-findings/

14. Sirintrapun SJ, Lopez AM. Telemedicine in cancer care. Am Soc Clin Oncol Educ Book 2018;38:540-545.

15. Coronavirus Preparedness and Response Supplement Appropriations Act of 2020. Public Law 116-123, March 6, 2020. Accessed June 29, 2020. Available at: https://www.congress.gov/116/plaws/publ123/PLAW116publ123.pdf

16. H.R. 748. Coronavirus Aid, Relief, and Economic Security Act (CARES Act). Accessed June 29, 2020. Available at: https://www.congress.gov/116/ bills/hr748/BILLS-116hr748enr.pdf

17. Kaiser Family Foundation Brief. Coverage and utilization of telemedicine services by enrollees in large employer plans. Accessed June 29, 2020. Available at: https://www.healthsystemtracker.org/brief/coverage-andutilization-of-telemedicine-services-by-enrollees-in-large-employerplans/

18. Liu R, Sundaresan T, Reed ME, et al. Telehealth in oncology during the COVID-19 outbreak: bringing the house call back virtually. JCO Oncol Pract 2020;16:289-293.

19. Ramsetty A, Adams C. Impact of the digital divide in the age of COVID-19. J Am Med Inform Assoc 2020;27:1147-1148.

20. Harvard Kennedy School Shorenstein Center on Media, Politics and Public Policy. Computer usage and access in low-income urban communities. Accessed June 29, 2020. Available at: https://journalistsresource.org/ studies/society/internet/computer-usage-access-low-income-urbancommunities/

21. Scott Kruse C, Karem P, Shifflett K, et al. Evaluating barriers to adopting telemedicine worldwide: a systematic review. J Telemed Telecare 2018; 24:4-12.

22. Bustillo NE, McGinty HL, Dahn JR, et al. Fatalism, medical mistrust, and pretreatment health-related quality of life in ethnically diverse prostate cancer patients. Psychooncology 2017;26:323-329.

23. Crossing the quality chasm: a new health system for the 21 st century. Washington, DC: Institute of Medicine, National Academy Press; 2001.

24. George SM, Hamilton A, Baker R. Pre-experience perceptions about telemedicine among African Americans and Latinos in South Central Los Angeles. Telemed J E Health 2009;15:525-530.

25. Pew Research Center. Mobile fact sheet. Accessed May 4, 2020. Available at: https://www.pewresearch.org/internet/fact-sheet/mobile/

26. National Cancer Institute. Age and cancer risk. Accessed May 16, 2020 Available at: https://www.cancer.gov/about-cancer/causes-prevention/ risk/age

27. Fowler $\mathrm{H}$, Belot $\mathrm{A}$, Ellis L, et al. Comorbidity prevalence among cancer patients: a population-based cohort study of four cancers. BMC Cancer 2020;20:2.

28. Adams JG. Emergency department overuse: perceptions and solutions. JAMA 2013;309:1173-1174.

29. Tung M, Sharma R, Hinson JS, et al. Factors associated with imaging overuse in the emergency department: a systematic review. Am J Emerg Med 2018;36:301-309.

30. Newton EH. Addressing overuse in emergency medicine: evidence of a role for greater patient engagement. Clin Exp Emerg Med 2017;4: 189-200.

31. Earle CC, Neville BA. Under use of necessary care among cancer survivors. Cancer 2004;101:1712-1719.

32. Ashwood JS, Mehrotra A, Cowling D, et al. Direct-to-consumer telehealth may increase access to care but does not decrease spending. Health Aff (Millwood) 2017;36:485-491.
33. Lyu $\mathrm{H}, \mathrm{Xu} T$, Brotman $\mathrm{D}$, et al. Overtreatment in the United States. PLoS One 2017; 12:e0181970.

34. Dans M, Kutner JS, Baker JN, et al. NCCN Clinical Practice Guidelines in Oncology: Palliative Care. Version 1.2020. Accessed April 27, 2020. To view the most recent version, visit NCCN.org

35. Riba MB, Donovan KA, Andersen B, et al. NCCN Clinical Practice Guidelines in Oncology: Distress Management. Version 2.2020. Accessed April 27, 2020. To view the most recent version, visit NCCN.org

36. Ferrell BR, Temel JS, Temin S, et al. Integration of palliative care into standard oncology care: American Society of Clinical Oncology clinical practice guideline update. J Clin Oncol 2017;35:96-112.

37. Commission on Cancer. 2020 Standards. Accessed April 27, 2020. Available at: https://www.facs.org/quality-programs/cancer/coc

38. National Accreditation Program for Breast Centers Standard 2.15: 2018 Edition. Accessed April 27, 2020. Available at: https://www.facs.org/ quality-programs/napbc/standards

39. Unger JM, Cook E, Tai E, et al. The role of clinical trial participation in cancer research: barriers, evidence, and strategies. Am Soc Clin Oncol Educ Book 2016;35:185-198.

40. Meng J, McLaughlin M, Pariera K, et al. A comparison between Caucasians and African Americans in willingness to participate in cancer clinical trials: the roles of knowledge, distrust, information sources, and religiosity. J Health Commun 2016;21:669-677.

41. Pariera KL, Murphy ST, Meng J, et al. Exploring willingness to participate in clinical trials by ethnicity. J Racial Ethn Health Disparities 2017;4 763-769.

42. Smirnoff $M$, Wilets $\mathrm{I}$, Ragin DF, et al. A paradigm for understanding trust and mistrust in medical research: the Community VOICES study. AJOB Empir Bioeth 2018;9:39-47.

43. Science 37 and AOBiome Complete Industry-First Virtual Clinical Trial Through Metasite (Decentralized) operating model. Accessed May 16, 2020. Available at: https://www.science37.com/science-37-aobiomecomplete-industry-first-virtual-clinical-trial-metasite-decentralized-operating-model/

44. Bobb MR, Van Heukelom PG, Faine BA, et al. Telemedicine provides noninferior research informed consent for remote study enrollment: randomized controlled trial. Acad Emerg Med 2016;23:759-765.

45. Clark JM, Heifetz LJ, Palmer D, et al. Telehealth allows for clinical trial participation and multimodality therapy in a rural patient with stage 4 nonsmall cell lung cancer. Cancer Treat Res Commun 2016;9:139-142.

46. FDA Guidance on Conduct of Clinical Trials of Medical Products during COVID-19 Public Health Emergency. Accessed April 28, 2020. Available at: https://www.fda.gov/media/136238/download

47. Hede K. Teleoncology gaining acceptance with physicians, patients. J Natl Cancer Inst 2010;102:1531-1533.

48. Mair F, Whitten $\mathrm{P}$, May $C$, et al. Patients' perceptions of a telemedicine specialty clinic. J Telemed Telecare 2000;6:36-40.

49. Mooi JK, Whop LJ, Valery PC, et al. Teleoncology for indigenous patients: the responses of patients and health workers. Aust J Rural Health 2012;20: 265-269.

50. Sabesan S, Simcox K, Marr I. Medical oncology clinics through videoconferencing: an acceptable telehealth model for rural patients and health workers. Intern Med J 2012;42:780-785.

51. Collie K, Kreshka MA, Ferrier S, et al. Videoconferencing for delivery of breast cancer support groups to women living in rural communities: a pilot study. Psychooncology 2007;16:778-782.

52. Doorenbos AZ, Demiris G, Towle C, et al. Developing the Native People for Cancer Control Telehealth Network. Telemed J E Health 2011;17: 30-34.

53. Zhou ES, Partridge AH, Blackmon JE, et al. A pilot videoconference group stress management program in cancer survivors: lessons learned. Rural Remote Health 2016;16:3863.

54. National Quality Forum. Creating a Framework to Support Measure Development for Telehealth. Accessed June 29, 2020. Available at: https://www.qualityforum.org/Publications/2017/08/Creating_a_Framework to Support Measure Development for Telehealth.aspx 